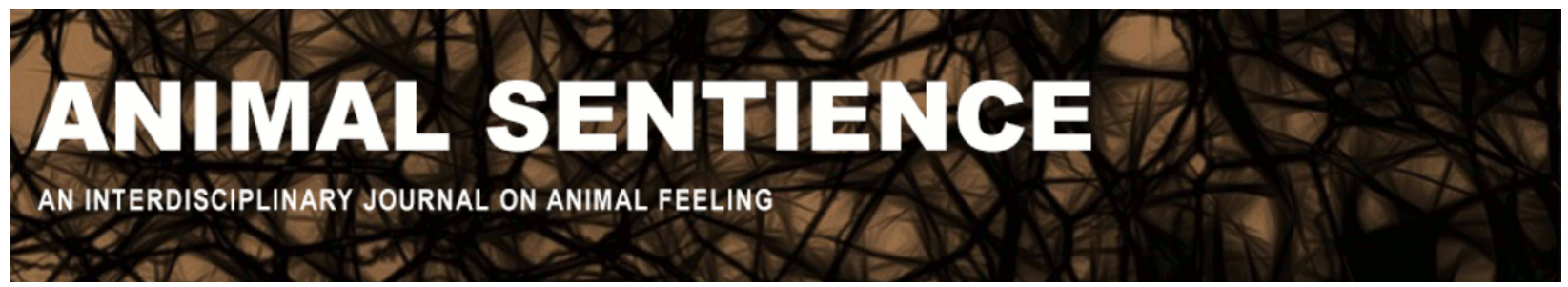

Segner, Helmut (2016) Why babies do not feel pain, or: How structure-derived functional interpretations can go wrong. Animal Sentience 3(26)

DOI: $10.51291 / 2377-7478.1042$

Date of submission: $2015-10-18$

Date of acceptance: 2015-12-13

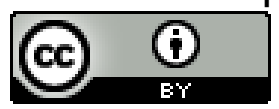

This article has appeared in the journal Animal

Sentience, a peer-reviewed journal on animal

cognition and feeling. It has been made open access,

free for all, by WellBeing International and deposited

in the WBI Studies Repository. For more information,

please contact

wbisr-info@wellbeingintl.org.

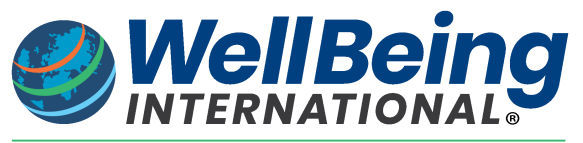

SOLUTIONS FOR PEOPLE, ANIMALS AND ENVIRONMENT 


\title{
Why babies do not feel pain, or: \\ How structure-derived functional interpretations can go wrong
}

Commentary on Key on Fish Pain

\author{
Helmut Segner \\ Department of Infectious Diseases and Pathobiology \\ University of Bern
}

\begin{abstract}
The response to pain involves a non-conscious, reflexive action and a conscious perception. According to Key (2016), consciousness - and thus pain perception - depends on a neuronal correlate that has a "unique neural architecture" as realized in the human cortex. On the basis of the "bioengineering principle that structure determines function," Key (2016) concludes that animal species such as fish, which lack the requisite cortex-like neuroanatomical structure, are unable to feel pain. This commentary argues that the relationship between brain structure and brain function is less straightforward than suggested in Key's target article.
\end{abstract}

\begin{abstract}
Helmut Segner helmut.segner@vetsuisse.unibe.ch is Professor and Head of the Centre for Fish and Wildlife Health, University of Bern, Switzerland. His research topics include fish toxicology and fish pathology. http://www.itpa.vetsuisse.unibe.ch/fiwi
\end{abstract}

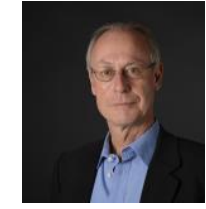

The central role of the cortex in pain perception is undisputed. However, is it indeed justified to interpret pain perception as an exclusive function of the cortex, or could other brain areas be involved? Key (2016) argues that phylogenetically old brain regions such as thalamus and brain stem (which, by the way, are present in fish) function only in "noxious processing" and do not contribute to the feeling of pain. A number of authors contradict this interpretation, however, and consider those older brain regions to be a constitutive part of a neuronal network mediating pain perception (e.g., Pessoa and Adolphs, 2011; Damasio and Carvalho, 2013; Garcia-Larrea and Peyron, 2013). If the feeling of pain does indeed depend on a "pain matrix" integrating multiple brain areas rather than a single brain structure, couldn't a certain form of pain perception already be possible in the absence of the cortex?

In this context it is interesting to recall that earlier in the $20^{\text {th }}$ century it had been the thalamus, not the cortex, that was considered the central site of pain perception in man. This was based on sound experimental observations on the relationship between pain perception and experimental manipulation of the cortex (Perl 2007). As stated by Edelman and Tononi (2000), "[M]any neuroscientists have emphasized particular neural structures whose activity correlates with conscious experiences. It is not surprising that different neuroscientists end up favouring different structures. As we shall see in a number of cases, it is likely that the workings of each structure may contribute to consciousness, but it is a mistake to expect that pinpointing particular locations in the brain ... will explain why their activity does or does not contribute to conscious experience." 
Another question concerning Key's hypothesis is whether pain perception is indeed only possible with the "unique neural architecture" of the human cortex. From an evolutionary (rather than a bioengineering) perspective, it is more likely that structures and functions evolved gradually rather than suddenly popping out of the blue. What about mammalian species with a less unique cortical structure than humans: are they able to feel pain? And if so, where to draw the line? When does cortical structure get too simple to support pain perception?

Nor should the possibility of convergent evolution (different structures performing the same or similar functions) be overlooked. How are we to understand, for instance, the capability of certain bird species to display complex behaviours such as mirror self-recognition (Prior et al., 2008), which have been interpreted as suggestive of some level of consciousness. Yet the higher brain functions of such bird species depend on a neuroanatomical structure - the "wulst" (Butler et al., 2005) - which has an organization that is clearly different from that of the cortex. In particular, the wulst lacks the "laminar and columnar organization" that is one of the essential features for conscious neuronal processing according to Key.

How difficult the interpretation of structure-function relationships can be, and how problematic it is to interpret the cortex as a kind of an evolutionary on-off-switch for pain perception can be illustrated by the debate on the ability of pre-term and term infants to feel pain. This question has long been the subject of controversy and debates. Methodologically, the brain imaging techniques used to study pain perception in adults are not applicable to babies, and hence the discussion of pain perception in babies relies largely on structure-function arguments (a situation comparable to the discussion of the existence of fish pain). In particular, the immature status of the central nervous system of infants and the lack of myelination of its nerve fibres had been interpreted as evidence that neonates were unable to feel pain. More recent research, however, using novel methodological approaches, has come to the conclusion that babies, at least from week 35-37 onward, are able to perceive pain after all (e.g., Fabrizzi et al., 2011).

When it comes to the question of pain perception in fish, we should be careful not to recapitulate history by over-interpretation of structural observations.

\section{References}

Butler, A. B., Manger, P. R., Lindahl, B. I. B., and Århem, P. (2005) Evolution of the neural basis of consciousness: a bird-mammal comparison. Bioessays 27(9): 923-936.

Damasio, A., and Carvalho, G. B. (2013) The nature of feelings: evolutionary and neurobiological origins. Nature Rev. Neurosci. 13: 143-152

Edelman, G. M., and Tononi, G. (2000) A universe of consciousness. Basic Books, New York.

Fabrizzi, L., Slater, R., Worley, A., Meek, J., Boyd, S., Olhede, S., and Fitzgerald, M. (2011) A shift in sensory processing that enables the developing human brain to discriminate touch from pain. Curr. Biol. 21: 1552-1558. 
Garcia-Larrea, L., and Peyron, P. (2013) Pain matrices and neuropathic pain matrices: a review. Pain 154: 529-543.

Key, B. (2016). Why fish do not feel pain. Animal Sentience 2016.003.

Perl, E. R. (2007) Ideas about pain, a historical view. Nature Rev. Neurosci. 8: 71-80.

Pessoa, L., and Adolphs, R. (2011) Emotion and the brain: multiple roads are better than one. Nature Rev. Neurosci. 12: 435-436.

Prior, H., Schwarz, A., and Güntürkün, O. (2008) Mirror-induced behavior in the magpie (Pica pica): evidence of self-recognition. PLoS Biol 6(8): e202. 